\title{
Science and faith in mind
}

\section{Stuart Sutherland}

Brains, Machines and Persons. By Donald MacKay. Pp.114. (Collins/W. Eerdmans: 1980.) Pbk £3.50, \$4.95.

BOTH as a brain scientist and as a Protestant, Professor Donald MacKay is an honest man. Brains, Machines and Persons gives a brief but stimulating and lucid account of the human brain and of models of its workings cast in the form of computer programs. This account is a preamble to an attempt to reconcile the scientific and the religious view of human beings. He makes a better shot at it than others, such as Sir John Eccles, who have confronted the same dilemma. Professor MacKay rightly eschews both the argument for free will based on the Heisenberg uncertainty principle and any form of interactionism between mind and body, though he does not set out the reasons why these proposals are unsatisfactory. (The first can only account for random behaviour whereas the outcome of deliberate choice is far from random; the second implies that the brain is not a physical system in the ordinary sense of the word since at some point it is being influenced by non-physical events.)

Mackay's own solution to the mindbody problem is that human beings can be viewed in two ways, from the inside as a series of mental processes (the I-story) and from the outside as a series of physical events. He does not deny that the workings of the brain and nervous system may be deterministic and, at least in principle, predictable. He resolves the problem of freedom of the will by arguing that if someone predicts from a knowledge of his own brain state that he will do something, his brain is itself changed by this knowledge: this change may lead to the prediction being falsified since the brain cannot take into account the effects of the change in its own state in order to predict its future behaviour without falling into an infinite regress. MacKay then raises the question "suppose a super-scientist. . . produced a specification of [your brain's] immediate future.... Would you be correct to believe it?"'. He argues that you would not, since when the super-scientist gave you his prediction, your brain state would change and hence his prediction might fail. This is an argument with which I have dealt elsewhere ("Is the Brain a Physical System" in Explanations in the Behavioral Sciences edited by $\mathrm{R}$. Borger and F. Cioffi, Cambridge University Press; 1970). The problem is that the superscientist might have taken into his own calculations the effects of telling you what you will do, and have delivered the prediction only after making sure that you will still do what he predicts even after being informed that you will do it. MacKay is right in thinking that if the brain scientist delivers all the thought processes that underlie his prediction, then your brain state may be changed and the prediction may fail: once again an infinite regress arises. But Mackay fails to note that you may have other good reasons for believing the super-scientist, for example, you may know that he always gets his predictions right.

Despite this flaw in MacKay's argument, there is something to be said for the theses that mental events and physical states of the brain are one and the same thing viewed in different ways and that we can only choose freely because we cannot ourselves predict what we will do. He argues that it is the latter aspect of people that makes each a morally responsible agent. Even if this were true, it leaves open the question of how we view others. If they can legitimately be viewed as complex physical systems, does it make sense to praise and blame them? To the extent that we know the cause of an action, we tend not to attribute praise or blame. Someone who becomes extremely bad-tempered because of a tumour in the hypothalamus does not deserve censure. Here MacKay draws a distinction between brain hardware and brain

\section{Michael Bradbury}

The Cerebral Microvasculature: Investigation of the Blood-Brain Barrier. Edited by Howard M. Eisenberg and Robert L. Suddith. Pp.342. (Plenum: 1980.) £24.89, \$39.50.

AFTER the idea of a blood-brain barrier arose at the turn of the century, there was prolonged controversy as to whether it was sited at the level of the capillary endothelium or at that of the sheath of glial end-feet. In 1946, Krogh showed great foresight in not only placing the barrier at the capillary level, but in considering it to have the typical properties of a cell membrane and perhaps to be capable of secretion, i.e. active transport. Physiological and ultrastructural studies in the whole animal have fully confirmed this interpretation, and it is now accepted that software. If the hardware has gone wrong, no moral responsibility is attached. If it is the program being executed in the brain that is at fault, then it is proper to attach blame. Ingenious though this argument is, it again seems fallacious: suppose we knew enough about someone to predict from his genetic make-up and his environmental history exactly what programs were running in his brain, would that not make us want to excuse him for evil acts?

MacKay makes further play with the distinction between the brain's hardware and software. He even suggests that one solution to the problem of resurrection would be to incorporate the program that runs in each individual's brain in some medium other than the human body. He faces the fact that in the distant future we may be able to build computers as intelligent as ourselves and having many, if not all, of the attributes that we value in ourselves (other than being born of man). $\mathrm{He}$ believes that the existence of such machines would not lower the status of human beings, though it would raise that of computers. I once asked him whether such a computer would be a candidate for entry into the kingdom of heaven: with his usual honesty he replied, after careful reflection, that he could see no reason why not.

Stuart Sutherland is Director of the Centre for Research on Perception and Cognition at the University of Sussex.

\section{Activity in the blood-brain barrier}

the cerebral endothelium functions like a tight epithelium and is capable of active transport.

The Cerebral Microvasculature contains the edited manuscripts from a symposium held at Galveston, Texas, in 1979. The first section deals with transport properties and permeability. It largely contains reports of the properties of isolated whole capillaries of cultured endothelial cells and of parts of capillaries, plasma and basement membranes for example. Among a number of interesting papers, the uptake of various solutes into isolated capillaries as a model for transport across the barrier in vivo is reviewed by Betz and Goldstein, and the biochemical properties of isolated capillaries are considered by Mršulja and Djuričić. Eisenberg and his colleagues discuss the demonstration of an ouabain- 